\title{
Original
}

\section{Localization and Phenotype of Resident Macrophages in the Dental Pulp during Rat Mandibular First Molar Development}

\author{
Yasunori MiYauchi ${ }^{*} * *$, Mitsuori MaYahara***, Ryuji SASA**, \\ Mitsuko INOUE** and Masanori NAKAMURA* \\ * Department of Oral Anatomy and Developmental Biology, Showa University School of Dentistry \\ 1-5-8 Hatanodai, Shinagawa-ku, Tokyo, 142-8555 Japan \\ (Chief: Prof. Masanori Nakamura) \\ ** Department of Pedodontics, Showa University School of Dentistry \\ 2-1-1 Kitasenzoku, Ohta-ku, Tokyo, 145-8515 Japan \\ (Chief: Prof. Mitsuko Inoue) \\ ***Dental Medicine Education Unit, Showa University School of Dentistry \\ 1-5-8 Hatanodai, Shinagawa-ku, Tokyo, 142-8555 Japan \\ (Chief: Associate Prof. Ryuta Kataoka)
}

\begin{abstract}
Many macrophages are recognized in dental pulp. However, their precise functional roles and the origin are not well understood. In this study, we analyzed the characterization and the localization of dental pulp macrophages during tooth development by immunohistochemistry and immunoelectron microscopy. The first mandibular molars at 1 week finished the tooth crown formation and the molars at 6 weeks finished the root formation. In the dental papilla of molars at 1 week, many $\mathrm{CD} 68^{+}$cells were detected. Some of $\mathrm{CD} 68^{+}$cells were invaded into the odontoblastic layer at the tip of cusp. A few MHC class $\mathrm{II}^{+}$cells were localized in the dental papilla. Most of $\mathrm{CD} 68^{+}$cells were $\mathrm{CD}^{+} 8^{+} / \mathrm{MHC}$ class $\mathrm{II}^{-}$cells. At 6 weeks, many $\mathrm{CD}^{+} 8^{+}$cells in the crown dental pulp were invaded in odontoblastic layer, while no $\mathrm{CD} 68^{+}$cells were detected at the odontoblastic layer in the root pulp. At this stage, most of $\mathrm{CD} 68^{+}$cells were $\mathrm{CD} 68^{+} / \mathrm{MHC}$ class $\mathrm{II}^{+}$cells. These findings indicated the different distribution of dental pulp macrophages in the crown and the root areas, which suggested that the factors for the localization of macrophages might be different in crown and root pulp. Phenotypic changes of macrophages from $\mathrm{CD} 68^{+} / \mathrm{MHC}$ class $\mathrm{II}^{-}$to $\mathrm{CD} 68^{+} / \mathrm{MHC}$ class $\mathrm{II}^{+}$suggested the functional maturation of dental pulp macrophages within the tooth development.
\end{abstract}

Key words: tooth development, resident macrophages, dental pulp.

The dental pulp is the part in the center of a tooth made up of a loose connective tissue and cells called odontoblasts. Each pulp organ is composed of a coronal pulp located centrally in the crown of teeth and the root or radicular pulp. The radicular (root) portion of the pulp are continuous with the periapical connective tissue through the apical foramen where blood vessels and nerve fibers are penetrated. ${ }^{1)}$

Macrophages form heterogeneous populations with regard to their morphological, functional, phenotypic and metabolic properties. Because of the heterogeneity, different organs contain specifically differentiated organ-specific macrophages called resident macrophages. ${ }^{2)}$ One of the specific function of macrophages is the antigen presentation to $\mathrm{T}$ cells by the binding of antigen on major histocompatibility complex (MHC) class II molecules on the their cell surface to the $\mathrm{T}$ cell receptors. ${ }^{3 \sim 5)}$

MHC class II positive cells have been reported in the dental pulp in human, ${ }^{6,7)}$ mice $^{8,9)}$ and rats. ${ }^{10 \sim 13)}$ Immunohistochemical studies indicated the accumulation of these cells along the dentin-pulp border by the cavity

(Received November 26, 2009; Accepted for publication December 15, 2009) 
preparation, which suggested the role of these cells for the immune defense against microorganisms and for the differentiation, migration ; and activation of odontoblasts. ${ }^{14)}$ On the other hand, it has been also indicated that odontoblasts synthesized and secreted cytokines such as interleukin-1 (IL-1) and tumor necrosis factor $\alpha(\mathrm{TNF} \alpha)$, which might activate immunocompetent cells in the dental pulp. ${ }^{15)}$ As these previous studies mainly focused on MHC class II positive cells located in the coronal region of the dental pulp, it has not been still clear whether these cells show the same distribution of phenotypes between coronal and radical areas of the dental pulp.

We previously indicated that the orientation and thickness of collagen fibers in dentin and the ultrastructure of odontoblasts were quite different between the coronal and root area of the tooth, which lead to suggest the functional heterogeneity of odontoblasts between the two areas of the tooth. ${ }^{16)}$ The heterogeneity of macrophages reflects differences in tissue distribution, maturation and activation in response to cell-derived or environmental signals. ${ }^{17,18)}$ Therefore, we examined in this study immunohistochemically to compare the distribution and phenotypes of macrophages located in coronal and radical areas of the dental pulp by using the specific antibodies to monocyte-macrophage lineage cells and MHC class II.

\section{Materials and Methods}

The experimental protocol used was reviewed and approved by the Animal Care Committee of Showa University.

\section{Animals and antibodies}

Specific pathogen free Wister strain female rats were purchased from Saitama Experimental Breeding Laboratory (Saitama, Japan) and maintained under routine conditions at the Laboratory Animal Center of Showa University.

Monoclonal antibodies to detect macrophages were mouse anti-rat CD68 (ED1) and mouse anti-rat MHC class II (OX6) antibodies, which were purchased from SEROTEC (Oxford, UK). Secondary antibodies used were goat anti-mouse IgG antibodies either conjugated with Alexa Fluor 488 or Alexa Fluor 594 purchased from Molecular Probes (Eugene, OR).

\section{Tissue preparation}

Mandibles at 1 and 6 weeks old rats were dissected and fixed with $4 \%$ paraformaldehyde in PBS and then decalcified with 10\% EDTA. After the decalcification, specimens were immersed in 5\%,15\%, and 30\%-sucrose, embedded in CRYO form (International Equipment Co., Needham, MA), and quick-frozen in a mixture of acetone and dry ice for immunohistochemistry. Some of the specimens were dehydrated with graded series of ethanol, passed through xylene and embedded in paraffin. Five micrometer thick sections were stained with Hematoxylin and Eosin.

\section{Immunohistochemical observations}

Ten micrometer thick frozen sections were air dried for $60 \mathrm{~min}$ and rinsed in PBS, and processed for the double immunohistochemical staining. Sections were first treated with $10 \%$ normal goat serum and then incubated with treated with ED1. After washing with PBS, sections were incubated with Alexa Fluor 594 conjugated goat antimouse IgG antibody, washed with PBS and incubated with OX6. After washing, sections were incubated with Alexa Fluor 488 conjugated antibody, and observed by Nikon Microphoto-FXA fluorescent microscope (Tokyo, Japan).

\section{Immunoelectron microscopic observation}

Some of the sections were processed for the immunoelectron microscopic detection of the MHC class II positive cells. The avidine-biotin-peroxidase complex technique using the Vectorstain-ABC kit, PK6200 (VECTOR, Burlingame, CA, USA) was applied. After incubation with 5\% normal goat serum, sections were incubated with a monoclonal antibody. After several rinses, sections were incubated with biotinized goat anti-mouse IgG antibody (Cappel, West Chester, PA, USA). After washing, sections were fixed with $2.5 \%$ glutaraldehyde for $15 \mathrm{~min}$, washed with PBS and followed by an incubation with avidine-biotinperoxidase complex for $30 \mathrm{~min}$. After washing, sections were incubated with $0.06 \%$ 3-3' diamino- 
benzidine tetrahydrochloride (DAB) (WAKO, Osaka, Japan) and $0.03 \% \mathrm{H}_{2} \mathrm{O}_{2}$ in $0.1 \mathrm{M}$ Tris- $\mathrm{HCl}$ buffer at $\mathrm{pH}$ 7.6. Sections were then post-fixed with $2 \%$ osmium tetraoxide, dehydrated with graded series of ethanol and embedded in EPON 812 (Birksher, England). Ultra-thin sections were stained faintly with uranyl acetate and lead citrate and examined with a HITACHI H-7000 transmission electron microscope.

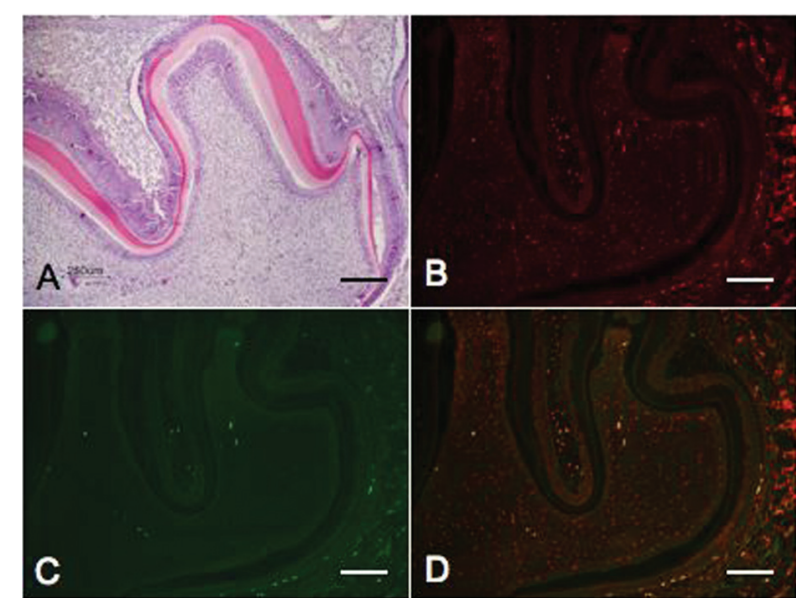

Fig. 1 Rat mandibular first molar at 1 week. Decalcified sections were stained with H-E (A) and immunostained with anti-CD68 (B) and anti-MHC class II (C) antibodies. D. Double staining of the section with anti-CD68 and anti-MHC class II antibodies. Bar $=250 \mu \mathrm{m}$.

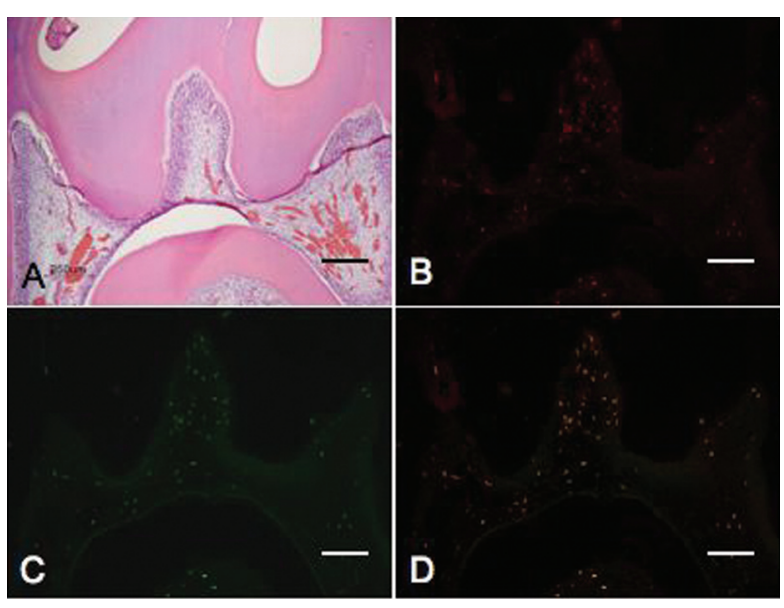

Fig. 2 The coronal portion of the rat mandibular first molar at 6 weeks. Decalcified sections were stained with H-E (A) and immunostained with anti-CD68 (B) and anti-MHC class II (C) antibodies. D. Double staining of the section with anti-CD68 and anti-MHC class II antibodies. $\mathrm{Bar}=250 \mu \mathrm{m}$.

\section{Results}

\section{Immunohistochemical detection of macrophages in the dental pulp during development}

At 1 week, rat mandibular first molars showed that morphogenesis of the crown was almost finished and started the development of root formation (Fig. 1A). In the dental pulp, many CD68 positive cells were

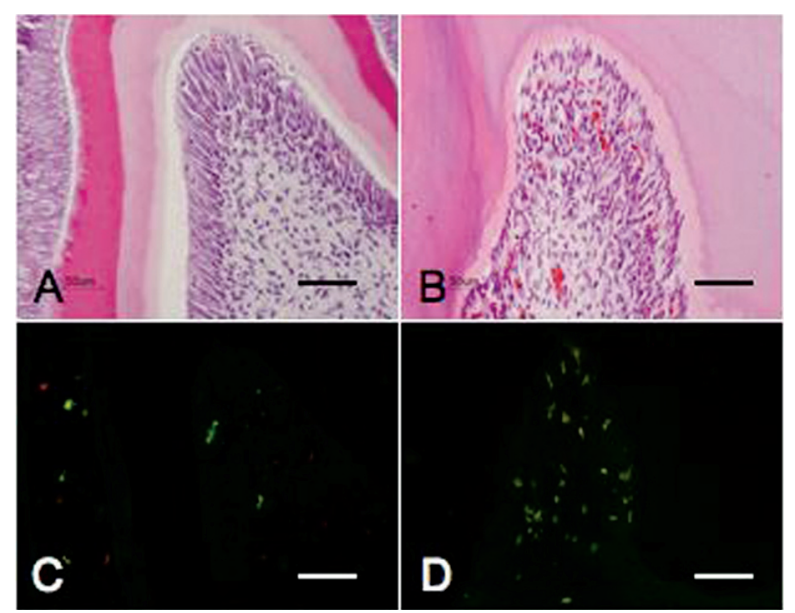

Fig. 3 Higher magnification of the coronal pulp at 1 week (A, C) and 6 weeks (B, D). A, C. H-E staining. C, D. Double staining of the section with anti-CD68 and anti-MHC class II antibodies. $\mathrm{Bar}=50 \mu \mathrm{m}$.

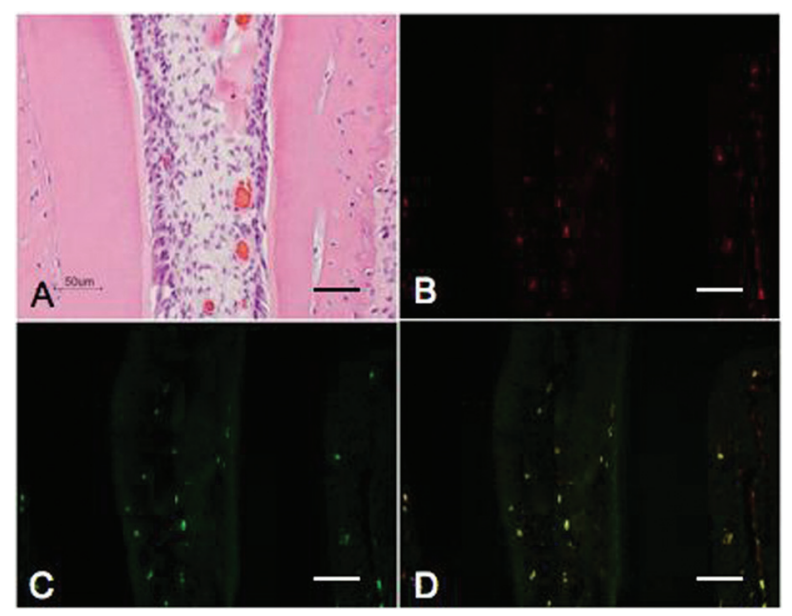

Fig. 4 The radicular portion of the rat mandibular first molar at 6 weeks. Decalcified sections were stained with $\mathrm{H}-\mathrm{E}$ (A) and immunostained with anti-CD68 (B) and anti-MHC class II (C) antibodies. D. Double staining of the section with anti-CD68 and anti-MHC class II antibodies. Bar $=250 \mu \mathrm{m}$. 


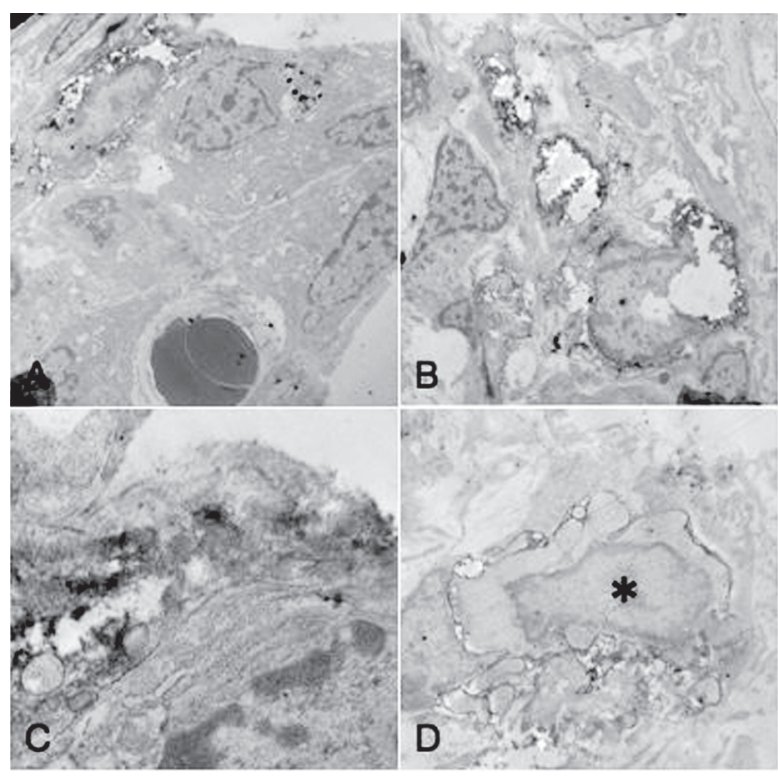

Fig. 5 Immunoelectron micrographs of MHC class II positive cells in the coronal $(\mathrm{A}, \mathrm{B}, \mathrm{C})$ and the radicular (D) portions of the dental pulp at 6 weeks. A. MHC class II positive cell closely associated with odontoblasts (*). B. Several immunopositive cells were aggregated. C. Higher magnification of the immunopositive cell. Arrows indicated the direct contanct between immunopositive cell and odontoblast $(*)$. D. MHC class II positive cells in the radicular portion. Bar $=2 \mu \mathrm{m}$ (A, B, D). Bar $=500 \mathrm{~nm}$ (D).

detected at this stage. These cells were scattered within the dental pulp and some of them were penetrated into the odontoblastic layer (Fig. 1B). MHC class II positive cells were only detected at the central part of the dental pulp (Fig. 1C). Double staining of the dental pulp indicated that most CD68 positive cells were MHC class II negative. Although CD68/MHC class II double positive were only detected at the central part of the dental pulp, MHC class II single positive cells were not detected at this stage (Fig. 1D). At the higher magnification, some migrating cells were detected in the odontoblastic layer (Fig. 3A). However, only some of these cells were CD68 positive (Fig. 3C). CD68/ MHC class II double positive cells were not detected in the odontoblastic layer (Fig. 3C).

At 6 weeks, the first mandibular molars erupted, started the functional occlusion and finished the root formation (Fig. 2A). In the coronal pulp, many CD68 positive cells were scattered within the pulp (Fig. 2B). In addition, MHC class II positive cells were also distributed within the pulp (Fig. 2C). Double staining of the coronal pulp showed that almost all of these cells were CD68/MHC class II double positive (Fig. 2D). At the higher magnification, many migrating cells were also detected in the odontoblastic layer (Fig. 3B). CD68/MHC class II double positive cells were penetrated into the odontoblastic layer (Fig. 3D).

CD68 positive cells at 1 week showed relatively smooth cell surface and round shape, while the cells at 6 weeks showed the larger cell bodies with developed cell processes (Fig. 3B, D).

At the radicular portion of the dental pulp, the root formation was finished and acellular and cellular cementum were formed on the root dentin. Odontoblasts aligned beneath predentin and odontoblasts in this region were shorter than the cells in the coronal region (Fig. $4 \mathrm{~A})$.

Many CD68 positive and MHC class II positive cells were detected in the radicular portion of the pulp (Fig. 4B, C). Almost all of these cells were CD68/MHC class II double positive (Fig. 4D). No positive cells were detected in the odontoblastic layer (Fig. 4D).

\section{Immunoelectron microscopic detection of $\mathrm{MHC}$ class II positive macrophages}

Almost all macrophages in the dental pulp of the mandibular first molars were CD68/MHC class II double positive at 6 weeks. Therefore, we next compared the ultrastructure of MHC class II positive cells in coronal and radicular portion of the dental pulp. MHC class II positive cells in the coronal region, especially between and/or beneath the odontoblastic layer, showed the irregular cell shape and developed cell processes (Fig. 5A, B). The nuclei of the cells located at the eccentric position. Some of the cells were independently located (Fig. 5A) and others were closely associated each other (Fig. 5B). Some of MHC class II positive cells were directly contacted with odontoblasts (Fig. 5C).

Most of MHC class II cells in the radicular portion of the pulp extruded the thick and dendrite-like cell 
processes (Fig. 5D). The cytoplasm of the cells were relatively electron-lucent and contained mitochondria and rough endoplasmic reticulum, while lysosomal structures were scarce and typical phagosomes were not recognized (Fig. 5D).

\section{Discussion}

Macrophages could be divided into two groups. One is the macrophage called resident macrophage which distributed ubiquitously under the normal condition and the other is the cells exudating in inflammatory foci. Previous studies indicated the distribution of immunocompetent cells in the dental pulp in healthy and/or disease conditions. ${ }^{9,19)}$ Zhang et al. described the two types of immunocompetent cells, CD11 ${ }^{-} \mathrm{F} 4 / 80^{+}$ cells and $\mathrm{CD} 11 \mathrm{c}^{+} \mathrm{F} 4 / 80^{-}$cells, in the mouse dental pulp. ${ }^{9)} \mathrm{CD} 11 \mathrm{c}^{+} \mathrm{F} 4 / 80^{-}$cells, but not $\mathrm{CD} 11 \mathrm{c}^{-} \mathrm{F} 4 / 80^{+}$ cells, migrated to the pulp-dentin border soon after the cavity preparation, indicating the existence of at least two distinct types of immunocompetent cells in the dental pulp. However, most of previous studies focused on the distribution of the cells in the coronal portion of the dental pulp. In this study, an immunohistochemical study showed the different distribution patterns of macrophages in coronal and radicular portions of the dental pulp of the normal first mandibular first molars at 6 weeks old rats. Some of macrophages in the coronal penetrated into the odontoblastic layer and contacted directly with odontoblasts while no macrophages in the root pulp located in the odontoblastic layer. Therefore, macrophages investigated in this study were resident macrophages in the dental pulp, which showed the different distribution patterns between the coronal and radicular portion of the pulp.

Chemokines are the key molecules for the macrophage migration. Odontoblasts constitutively express several types of chemokines, beta-defensin-1 and beta-defen$\sin -2 .^{20 \sim 23)}$ Some of these factors might be the candicate molecules for the macrophage migration.

Immunoelectron microscopic study indicated the direct contact of macrophages with odontoblasts in the coronal portion of the pulp. In this study, we could not detect the direct contact of macrophages with odontoblasts in the radicular portion of the pulp. Previous studies suggested the role of macrophages for the differentiation of odontoblasts during the regeneration process of the dental pulp. ${ }^{19,24)}$ The recent study indicated the expression of Toll-like receptor 2 (TLR2) and TLR4 as well as CCR6 by odontoblasts and suggested the regulation of immune response by odontoblasts. ${ }^{25)}$ These results strongly suggest the close association of odontoblasts and macrophages for the defense mechanism of the dental pulp against the foreign antigens and/or stimuli. While morphological difference of odontoblasts and the orientation and the thickness of collagen fibers in dentin matrix were mentioned between coronal and radicular portions of the pulp, it has not been clarified the functional differences of odontoblasts between two areas of the dental pulp. Our finding suggest the functional heterogeneity of macrophages between coronal and radicular portions of the dental pulp, which might reflect the different regulation of immune response at the two areas in the dental pulp.

Only CD64 single-positive macrophages were detected in the dental pulp of the first mandibular molars at 1 week. MHC class II positive cells were detetcted at 6 weeks. These cells coexpressed CD64. Okiji et al. ${ }^{12)}$ also reported that MHC class II positive cells were not detected at this stage. These results indicated the functional maturation of macrophages within the dental pulp during the development.

According to the concept of the mononuclear phagocyte system proposed by van Furth et al., blood monocytes originated from precursor cells in the bone marrow migrate into various tissues and differentiate into resident macrophages. ${ }^{26,27)}$ These macrophages were characterized as a short-lived population without proliferation capacity. ${ }^{26,27)}$ On the contrary, conflicting data have been indicated by several investigators on the development and differentiation of resident macrophages. During ontogeny, primitive macrophages develop, proliferate and differentiate into fetal macrophages before the production of monocytes in the fetal 
hematopoietic tissues. ${ }^{28,29)}$ Resident macrophages are capable of proliferation under various experimental conditions. ${ }^{30,31)}$ Our preliminary tooth organ culture study also suggested the proliferation of macrophages in the dental papilla [data not shown]. These results strongly suggest possibility of the in situ proliferation and maturation of macrophages in the dental pulp during the development.

Acknowledgements The part of this study was supported by the Grant-in-Aid for Scientific Research (16659051, 17076001, 18592008) and High-Tech Research Center Project for Private Universities from Ministry of Education, Culture, Sports, Science and Technology, Japan.

\section{References}

1) Avery JK: Pulp, In Bhaskar SN (ed): ORBAN'S Oral Histology and Embryology. St. Louis, 1976, The C.V. Mosby Company, pp 141-181

2) Naito M, Umeda $S$, Yamamoto T, Moriyama H, Umezu H, Hasegawa G, Usuda H, Shultz LD, Takahashi K: Development, differentiation, and phenotypic heterogenetity of murine tissue macrophages. J Leukoc Biol, 59: 133-138, 1996

3) Kleijmeer MJ, Ossevoort MA, van Veen CJ, van Hellemond JJ, Neefjes JJ, Kast WM, Melief CJ,Geuze HJ: MHC class II compartments and the kinetics of antigen presentation in activated mouse spleen dendritic cells. J Immunol, 54: 57155724, 1995

4) Marks MS, Germain RN, Bonifacino JS: Transient aggregation of major histocompatibility complex class II chains during assembly in normal spleen cells. J Biol Chem, 270: 10475-10481, 1995

5) Banchereau J, Steinman RM: Dendritic cells and the control of immunity. Nature, 392: 245-252, 1998

6) Jontell M, Gunraj MN, Bergenholtz G: Immunocompetent cells in normal dental pulp. J Dent Res, 66: 1149-1153, 1987

7) Angelova A, Takagi T, Okiji T, Kaneko T, Yamashita Y: Immunocompetent cells in the pulp of human deciduous teeth. Arch Oral Biol, 49: 29-36, 2004

8) Tsuruga E, Sakakura Y, Yajima T, Shide N: Appearance and distribution of dendritic cells and macrophages in dental pulp during early postnatal morphogenesis of mouse mandibular first molars. Histochem Cell Biol, 112: 193-204, 1999

9) Zhang J, Kawashima N, Suda H, Nakano Y, Takano Y, Azuma M: The existence of CD11 ${ }^{+}$sentinel and F4/80 ${ }^{+}$ interstitial dendritic cells in dental pulp and their dynamics and functional properties. Int Immunol, 18: 1375-1384, 2006

10) Jontell M, Okiji T, Dohlgren U, Bergenholtz G: Immune defense mechanisms of the dental pulp. Crit Rev Oral Biol Med, 9: 179-200, 1998

11) Okiji $T$, Kawashima N, Kosaka $T$, Matsumoto A, Kobayashi C, Suda H: An immunohistochemical study of the distribution of immunocompetent cells, especially macrophages and Ia antigen-expressing cells of heterogeneous populations, in normal rat molar pulp. J Dent Res, 71: 1196-1202, 1992

12) Okiji T, Kosaka T, Kamal AM, Kawashima N, Suda H: Age-related changes in the immunoreactivity of the monocyte/macrophage system in rat molar pulp. Arch Oral Biol, 41: 453-460, 1996

13) Ohshima H, Kawahara I, Maeda T, Takano Y: The relationship between odontoblasts and immunocompetent cells during dentinogenesis in rat incisors: an immunohistochemical study using OX6-monoclonal antibody. Arch Histol Cytol, 57: 435-447, 1994

14) Kawagishi E, Nakakura-Ohshima K, Nomura S, Ohshima $\mathrm{H}$ : Pulpal responses to cavity preparation in aged rat molars. Cell Tissue Res, 326: 111-122, 2006

15) Hahn CL, Liewehr FR: Innate immune responses of the dental pulp to caries. J Endod, 33: 643-651, 2007

16) Nakamura M: Regional ultrastructural and cytochemical comparisons of the epithelial-mesenchymal interface during rat incisor development. J Craniofac Genet Dev Biol, 4: 329-341, 1984

17) Damoiseaux JG, Dopp EA, Beelen RH, Dijkstra CD: Rat bone marrow and monocyte cultures: influence of culture time and lymphokines on the expression of macrophage differentiation antigens. J Leukoc Biol, 46: 246-253,1989

18) Falk LA, Vogel SN: Differential production of IFN-alpha/ beta by CSF-1- and GM-CSF-derived macrophages. J Leukoc Biol, 48: 43-49, 1990

19) Nakakura-Ohshima K, Watanabe J, Kenmotsu S, Ohshima $\mathrm{H}$ : Possible role of immunocompetent cells and the expression of heat shock protein-25 in the process of pulpal regeneration after tooth injury in rat molars. J Electron Microsc, 52: 581-591, 2003

20) Mantovani A, Sica A, Sozzani S, Allavena P, Vecchi A, Locati M: The chemokine system in diverse forms of macrophage activation and polarization. Trends Immunol, 25: 677-686, 2004

21) Petkovic V, Moghini C, Paoletti S, Uguccioni M, Gerber $\mathrm{B}$ : Eotaxin-3/CCL26 is a natural antagonist for CC chemokine receptors 1 and $5 \mathrm{~A}$ human chemokine with a regulatory role. J Biol Chem, 279: 23357-23363, 2004

22) Shellenberger TD, Wang M, Gujrati M, Jayakumar A, Strieter RM, Burdick MD, Ioannides CG, Efferson CL, El-Naggar AK, Roberts D, Clayman GL, Frederick MJ: BRAK/CXCL14 is a potent inhibitor of angiogenesis and a chemotactic factor for immature dendritic cells. Cancer Res, 64: 8262-8270, 2004

23) Dommisch H, Winter J, Acil Y, Dunsche A, Tiemann M, Jepsen S: Human beta-defensin (hBD-1, -2) expression 
in dental pulp. Oral Microbiol Immunol, 20: 163-166, 2005

24) Kamal AM, Ojiki T, Suda H: Response of class II molecule-expressing cells and macrophages to cavity preparation and restoration with 4-META/MMA-TBB resin. Int Endod J, 33: 367-373, 2000

25) Veerayutthwilai O, Byers MR, Pham TT, Darveau RP, Dale BA: Differential regulation of immune responses by odontoblasts. Oral Microbiol Immunol, 22: 5-13, 2007

26) van Furth R, Cohn ZA, Hirsch JG, Humphrey JH, Spector WG, Langevoort HL: The mononuclear phagocyte system: a new classification of macrophages, monocytes, and their precursor cells. Bull World Health Organ, 46: 845852,1972

27) van Furth R: Origin and turnover of monocytes and macrophages, cell kinetics of the inflammatory reactions. In Invesen $\mathrm{OH}$ (ed): Current Topics in Pathology. vol 79.
Heidelberg, 1980, Springer-Verlag, pp 1-30

28) Takahashi K, Yamamura F, Naito M: Differentiation, maturation, and proliferation of macrophages in the mouse yalk sac: a light-microscopic, enzyme-cytochemical, immunohistochemical, and ultrastructural study. J Leukoc Biol, 45: 87-96, 1989

29) Higashi K, Naito M, Takeya M, Ando M, Araki S, Takahashi $\mathrm{K}$ : Ontogenic development, differentiation, and phenotypic expression of macrophages in fetal rat lung. J Leukoc Biol, 51: 444-454, 1992

30) Widmann JJ, Fahimi HD: Proliferation of mononuclear phagocytes (Kupffer cells) and endothelial cells in regenerating rat liver. Am J Pathol, 80: 349-366, 1975

31) Yamada M, Naito M, Takahashi K: Kupffer cell proliferation and glucan-induced granuloma formation in mice depleted of blood monocytes by strontium-89. J Leukoc Biol, 47: 195-205, 1990 